\title{
Computational Investigation of Lightning Strike Effects on Aircraft Components
}

\author{
Ravichandran Ranjith* and Rho Shin Myong** \\ Dept. of Aerospace and System Engineering and Research Center for Aircraft Parts Technology, Gyeongsang National University, \\ Jinju, Gyeongnam 660-701, South Korea
}

\section{Sangwook Lee L*** $^{* *}$}

Research Center for Aircraft Parts Technology, Gyeongsang National University, Jinju, Gyeongnam 660-701, South Korea

\begin{abstract}
A lightning strike to the aircraft seriously affects the aircraft and its components in various ways. As one of the most critical threats to the flight safety of an aircraft, fuel vapour ignition by lightning can occur through various means, notably through hot spot formation on the fuel tank skins. In this study, a coupled thermal-electrical approach using the commercial software ABAQUS is used to study the effects of a lightning strike on aircraft fuel tanks. This approach assumes that the electrical conductivity of a material depends on temperature, and that a temperature rise in a material due to Joule heat generation depends on electrical current. The inter-dependence of thermal and electrical properties-the thermal-electrical couplingis analyzed by a coupled thermal-electrical analysis module. The analysis elucidates the effects of different material properties and thicknesses of tank skins and identifies the worst case of lightning zones.
\end{abstract}

Key words: lightning, fuel vapour ignition, hot spot formation, coupled thermal-electrical approach

\section{Nomenclature}

AI

AL I

AL II

CFRP

CFRP I

CFRP II

i

$\mathrm{J}$

k

$K_{i j}$

q

r action integral

$1 \mathrm{~mm}$ thick aluminium fuel tank

$2 \mathrm{~mm}$ thick aluminium fuel tank

carbon fibre reinforced polymer

$1 \mathrm{~mm}$ thick CFRP fuel tank

$2 \mathrm{~mm}$ thick CFRP fuel tank

transient lightning current

current density entering the control volume across its surface $\mathrm{S}$

thermal conductivity matrix

submatrices of fully coupled Jacobian matrix

heat flux per unit area of the body

internal heat generated $\mathrm{r}_{\mathrm{c}}$

$\mathrm{R}$

$\mathrm{R}_{\varphi}$

$\mathrm{R}_{\theta}$

U

$\mathrm{V}$

W

$\delta \varphi$

$\Delta \varphi$

$\Delta \theta$

$\rho$

$\sigma^{\mathrm{E}}$

$\varphi$ internal volumetric current source per unit volume

resistance of the material

electrical potential residual vector

thermal residual vector

internal energy

control volume with surface $S$

electrical energy dissipated

arbitrary electrical potential field

correction to incremental electrical potential

correction to incremental temperature

density of the material

electrical conductivity matrix

electrical potential
This is an Open Access article distributed under the terms of the Creative Commons Attribution Non-Commercial License (http://creativecommons.org/licenses/by$\mathrm{nc} / 3.0 /$ ) which permits unrestricted non-commercial use, distribution, and reproduction in any medium, provided the original work is properly cited. (c) * Graduate student

** Professor, corresponding author: myong@gnu.ac.kr *** Visiting scholar 


\section{Introduction}

Aircraft flight safety is affected by many atmospheric disturbances, among which lightning is a significant one. Lightning strikes to an aircraft can result in serious effects on the aircraft, such as structural damage, melting of skin, fuel vapour ignition, or in the worst case, destruction of the whole aircraft. The effects of lightning strikes may be classified as direct and indirect effects. Effects, such as pitting or melt-through of the skins, resistive heating, and fuel vapour ignition, are classified as direct effects, and interferences made by lightning strike to the navigation systems and other electronic equipment are classified as indirect effects $[1,2]$.

Lightning originates from the charged centres of clouds, especially cumulonimbus clouds. The charges in the cloud create a leader, which induces another leader of the opposite charge in another place like another cloud or the ground. When the leaders of opposite charges meet, they make a conductive path that enables charge transfer between the clouds, which results in a lightning flash. Lightning is classified as intra-cloud lightning, cloud-to-cloud lightning and cloud-to-ground lightning based on the regions where the leaders originate. In some cases, an aircraft connects the two approaching leaders, and hence it is assumed to be in the conductive path, which makes the aircraft a victim of a lightning strike. In other words, when lightning strikes an aircraft, all of the lightning current passes through the aircraft, which results in some direct or indirect effects on the aircraft.

The fuel system of the aircraft faces the most serious problem of fuel vapour ignition. The fuel system is a very large system distributed throughout the aircraft, and its fuel vapours can catch fire in different ways. The lightning may attach to the fuel tank vents and bring about ignition, or the fuel vapour may be ignited by lightning when the skin is melted and the fuel vapour is directly exposed to the lightning, or the fuel vapours may be ignited by the electrical sparks released by components inside the fuel tank, or the ignition can be initiated by hot spot formation on the fuel tank skins [2, 3]. This study considers the fuel vapour ignition due to hot spot formation and discusses it in detail.

Fuel vapour ignition has been recorded to be the cause of the accidents of a several dozen civil and military aircrafts $[1,4]$. Fuel vapour ignition is a hazardous effect brought about by lightning and may result in the explosion of the fuel tank and ultimately the loss of the aircraft and the lives in it. The explosion of a fuel tank by fuel vapour ignition can be prevented by measures such as inerting, containment, foaming and elimination of ignition sources $[5,6]$. In this study, it is assumed that the fuel vapour is ready to ignite and all the other factors favour ignition.

Most of the previous research studied lightning effects experimentally by simulating lightning currents based on the definitions given by the SAE International (formerly the Society of Automotive Engineers) committee. In this study, a computational method is used to study the lightninginduced effects on aircraft fuel tanks. Transient changes in the temperature in the fuel tank are simulated under a given time history of lightning current. Various parameters that influence lightning effects, such as tank skin material, tank skin thickness and different lightning zones are analyzed [7].

Details of the lightning zones of an airplane and of the electrical current waveform are described in section 3 . The basics of the coupled electrical-thermal analysis procedure are given in section 4 . The analysis model of a fuel tank is explained in section 5. And the results and discussion are provided in section 6 .

\section{Significance of Lightning Certification}

An aircraft has to meet the requirements set by the certification authority to obtain flight certification. The lightning certification of an aircraft is critical because lightning represents an important safety hazard to the aircraft and the lives aboard. Lightning protection requirements have been included in the collection of Federal Aviation Regulations (CFRs) and Advisory Circulars (ACs) to prevent catastrophic accidents and to enable an aircraft to fly safely and land at a suitable airport. These requirements apply to the whole aircraft, but more specifically, to the fuel system and other critical and essential flight systems. Initially, the requirements were formulated on the assumption that hazardous lightning effects were limited to the external structure or to components directly exposed to lightning strikes, and that their protection could be achieved if they were adequately bonded to the main airframe. However, because of this assumption, designers neglected other effects and such negligence was the reason for several catastrophic accidents, which were brought about by electrical arcing among fuel tank components and by burnout of flight electrical components. The first sentence of CFR 25.581 clearly says "The airframe must be protected against catastrophic effects of lightning." Then a separate regulation, CFR 25.594, introduces specific attention to aircraft fuel systems.

The first airplane - lightning - protection design and test standards were published by the Federal Aviation Administration (FAA) in its Advisory Circular 25-3, later 
reprinted as AC 20-53, which dealt with lightning protection of airplane fuel systems, and by the US Department of Defense (DOD) in Military Standard MIL-B-5087, which dealt with provision for electrical bonding in airplane structures and equipment. However, the definition of lightning strike zones was completely absent in MIL-B-5087 and poorly defined in AC 20-53. Moreover, the early standards failed to define acceptable test methods. Hence, lightning related accidents continued to occur, even to aircrafts in compliance with AC 20-53 and MIL-B-5087. As a result, the SAE committee $\mathrm{AE}-4 \mathrm{~L}$ was formed and as the first task, the committee published a report entitled, "Lightning Test Waveforms and Techniques for Aerospace Vehicles and Hardware." The report included the definition of a standard severe lightning flash current waveform comprised of four current components, designated A, B, C and D, together with a set of methods for utilizing the standardized currents. Nowadays, a civil aircraft must properly meet the lightning certification requirements based on the flash current waveform to obtain certification.

\section{Simulation of Lightning}

\subsection{Lightning zoning}

An aircraft is divided into different zones based on the attachment and possibility of a lightning strike. Lightning strike analysis of each zone is based on some lightning current components that are assigned to the zone. These zones are defined by the SAE committee in ARP5414A as follows [8]:

Zone 1A: Initial attachment point with low possibility of lightning channel hang-on.

Zone 1B: Initial attachment point with high possibility of lightning channel hang-on.

Zone 1C: Transition zone for first return stroke.

Zone 2A: A swept-stroke zone with low possibility of lightning channel hang-on.

Zone 2B:A swept-stroke zone with high possibility of lightning channel hang-on.

Zone 3: Portions of the airframe that lie within or between the other zones, which may carry substantial amounts of electrical current by conduction between areas of direct or swept stroke attachment points.

These zone definitions given by the FAA or SAE are based on the previous in-flight experiences of aircrafts with similar designs or lightning strike tests on sub-scale models $[5,9]$. Hence these definitions are only general and should not be taken for a particular aircraft. There are other methods for determining the lightning zones of an aircraft. One of them is the rolling sphere model used by British Aerospace (BAe). Another method is probabilistic zoning, developed by ONERA (the French Aerospace Laboratory), which defines zones in terms of the probability of lightning to strike the aircraft. Probabilistic zoning can be applied to the new generation of aircrafts that are non-conventional in their geometry [10]. For our study, we consider the zones $2 \mathrm{~A}$ and 2B; their applicable current components, amplitudes, and time durations are taken from the SAE International.

\subsection{Lightning current waveforms}

The lightning environment is simulated by a set of lightning current waveforms defined by the SAE committee. The waveforms include four different current components, A, B, C and D, which are used for different time intervals.

The current components all together represent a real lightning environment but not all the components are used for analysis. Only a specified set of current components are used for different lightning zones as defined in ARP 5414A. The current waveforms are used not to exactly replicate lightning but to replicate the effects of lightning.

In experimental lightning testing, due to some practical difficulties, the lightning current waveforms are not applied in the same order as defined. The short duration pulses (A/D) are applied first followed by the long duration pulses (B/C), as in real lightning [11]. Components A, B and D are defined by the double exponential functions and component $\mathrm{C}$ is a rectangular current component. Component $\mathrm{A}$ is a high current component and $\mathrm{D}$ is roughly half of component A. Component B is an intermediate component and $\mathrm{C}$ is a continuing current meant to transfer $200 \mathrm{C}$ of charges. The peak amplitudes and time durations of these components are explained in Fig. 1.

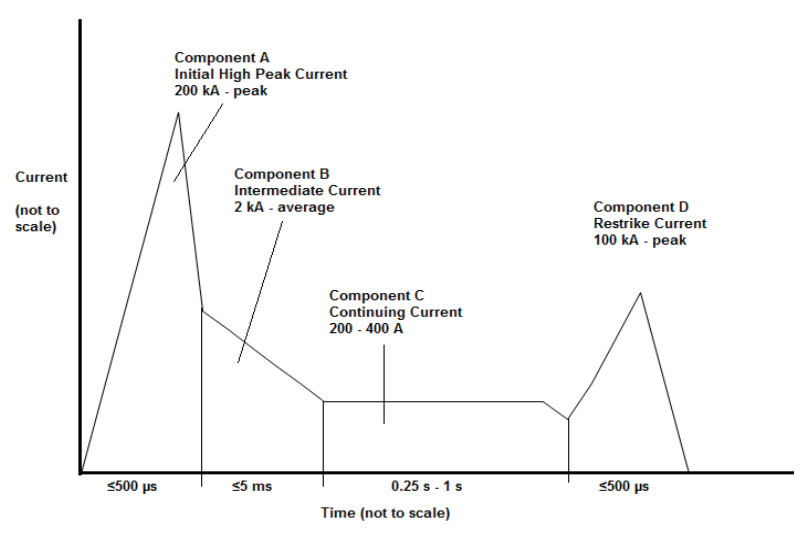

Fig. 1. Lightning current waveforms defined by the SAE committee. 


\section{Numerical Tool}

\subsection{Governing equations}

The numerical tool used for simulation is the commercial software ABAQUS, which uses the finite element method. The coupled thermal-electrical analysis module of the ABAQUS is utilized to analyse the coupling between thermal and electrical fields. In this coupled module, the conductivity in the electrical problem is considered temperature-dependent while the internal heat generated (Joule heating) in the thermal problem is considered a function of the electrical current [12].

The electrical field is described by Maxwell's equation of conservation of charge whereas the thermal field is described by the energy balance relation. The governing equations for the thermal and electrical fields are given by

$$
\int_{\mathrm{V}} \frac{\partial \delta \varphi}{\partial \mathrm{x}} \cdot \sigma^{\mathrm{E}} \cdot \frac{\partial \varphi}{\partial \mathrm{x}} \mathrm{dV}=\int_{\mathrm{V}} \delta \varphi \mathrm{r}_{\mathrm{c}} \mathrm{dV}+\int_{\mathrm{S}} \delta \varphi \mathrm{J} \mathrm{d} S
$$

and

$$
\int_{\mathrm{V}} \rho \dot{\mathrm{U}} \delta \theta \mathrm{dV}+\int_{\mathrm{V}} \frac{\partial \delta \theta}{\partial \mathrm{x}} \cdot \mathrm{k} \cdot \frac{\partial \theta}{\partial \mathrm{x}} \mathrm{dV}=\int_{\mathrm{V}} \delta \theta \mathrm{rdV}+\int_{\mathrm{S}} \delta \theta \mathrm{qdS}
$$

where $\mathrm{V}$ is the closed control volume with surface $\mathrm{S}, \delta \varphi$ is an arbitrary electrical potential field, $\sigma^{\mathrm{E}}$ is the electrical conductivity matrix, $\varphi$ is the electrical potential, $r_{c}$ is the internal volumetric current source per unit volume, $J$ is the current density entering the control volume across $S, \rho$ is the density of the material, $U$ is the internal energy, $\mathrm{k}$ is the thermal conductivity matrix, $\mathrm{q}$ is the heat flux per unit area of the body flowing into it, and $r$ is the internal heat generated.

Equations (1) and (2) are then discretised. The coupling is provided by Jacobian contributions, $\mathrm{K}_{\mathrm{ij}}$, which result in an asymmetric system of equations. The coupled thermalelectrical equation is then obtained in the form of an asymmetric matrix as

$$
\left[\begin{array}{ll}
\mathrm{K}_{\varphi \varphi} & \mathrm{K}_{\varphi \theta} \\
\mathrm{K}_{\theta \varphi} & \mathrm{K}_{\theta \theta}
\end{array}\right]\left\{\begin{array}{c}
\Delta \varphi \\
\Delta \theta
\end{array}\right\}=\left\{\begin{array}{l}
\mathrm{R}_{\varphi} \\
\mathrm{R}_{\theta}
\end{array}\right\}
$$

where $\mathrm{K}_{\mathrm{ij}}$ are submatrices of the fully coupled Jacobian matrix, $\Delta \varphi$ and $\Delta \theta$ are the corrections to the incremental electrical potential and temperature, and $\mathrm{R}_{\varphi}$ and $\mathrm{R}_{\theta}$ are the electrical potential and thermal residual vectors, respectively.

The coupled thermal-electrical analysis module allows for specifying the fraction of electrical energy released as internal heat through the Joule heat fraction option in the material definition. Here the Joule heat fraction is taken as one, assuming that all the electrical energy is converted into heat.

\subsection{Solution methods}

The coupled equations are solved simultaneously for electrical potential and temperature at the nodes by employing Newton's method. These coupled equations can be solved in two ways based on the strength of the coupling: exact implementation and approximate implementation. If the coupling is strong and the equations are solved without any approximations, the strongly coupled equations are solved by exact implementation. If the coupling is considered weak and the off-diagonal matrices in (3) are assumed to be zero, these weakly coupled equations are solved by approximate implementation. As default, the exact implementation is used by the solver [13].

The transient analysis in the coupled thermal-electrical analysis module is employed with an automatic time increment option for our analysis. The maximum allowable emissivity change is 0.3 and the maximum allowable temperature change is $10,000 \mathrm{~K}$ in all the analyses, except the zone 2A analysis of CFRP I, in which the maximum allowable temperature change is $1,000 \mathrm{~K}$. Each current component is assigned individual time steps, and the duration of the time step is the same as that of the corresponding current component.

\subsection{Validation of the numerical tool}

The numerical tool used for our analysis was validated previously [14] for CFRP composites. A delamination area was predicted by the coupled thermal-electrical analysis module and proven to qualitatively match closely with the experimental results in [14]. Similar contours obtained by the ABAQUS showing the delamination area are regenerated as Fig. 2, and these contours of the

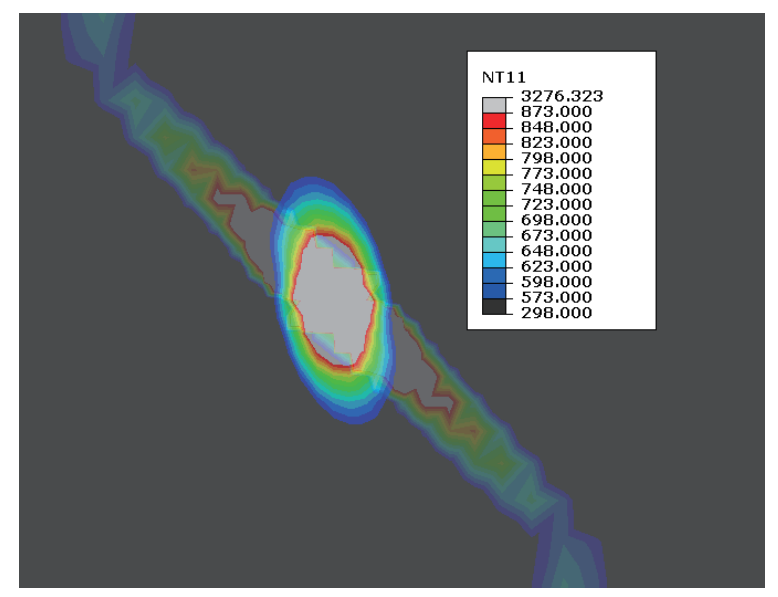

Fig. 2. Delamination area of a CFRP specimen predicted by the ABAQUS (shown for validation). 
delamination area also matches qualitatively well with the experimentally obtained ultrasonic C-scan results in [14]. Since the tool is valid for CFRP composites, it may also be used for the same type of analysis on CFRP composites of different geometries. Therefore, we chose the coupled thermal-electrical analysis module of the ABAQUS for our analysis.

\section{Fuel Tank Model}

\subsection{Geometry of the fuel tank}

The fuel tank considered for analysis is an integral fuel tank in which the fuel is in direct contact with the tank skin. An integral fuel tank has the advantage of partially balancing the lift force generated by the wing and hence the structural members of lesser strength than conventional ones can be used. The fuel tank chosen for analysis is a rectangular tank with dimensions $4,800 \mathrm{~mm} \times 1,400 \mathrm{~mm} \times$ $700 \mathrm{~mm}$. Four rectangular tanks were designed with two different skin thicknesses, $1 \mathrm{~mm}$ and $2 \mathrm{~mm}$, and two different fabrication materials, CFRP and aluminium. For clarity, the tank configurations used in the analysis are called CFRP I (1 mm CFRP tank), CFRP II (2 mm CFRP tank), AL I (1 mm aluminium tank), AL II ( $2 \mathrm{~mm}$ aluminium tank). The tank is divided equally into three sections by two inner walls. The top skin is extended beyond the tank dimensions to represent the wing skin.

\subsection{Initial and boundary conditions}

The lightning strike point where the lightning current attaches to the tank is the centre point of the top surface. The centre point of the bottom surface is assigned the zero potential boundary condition. The tank is assumed to be at an ambient temperature of $298 \mathrm{~K}$ initially, and the temperature fields are calculated by the coupled thermalelectrical analysis module. The top surface is allowed for surface radiation with ambient temperature of $298 \mathrm{~K}$ and the emissivity distribution is uniform at 0.9 . The fuel tank model with the boundary conditions is shown in Fig. 3.

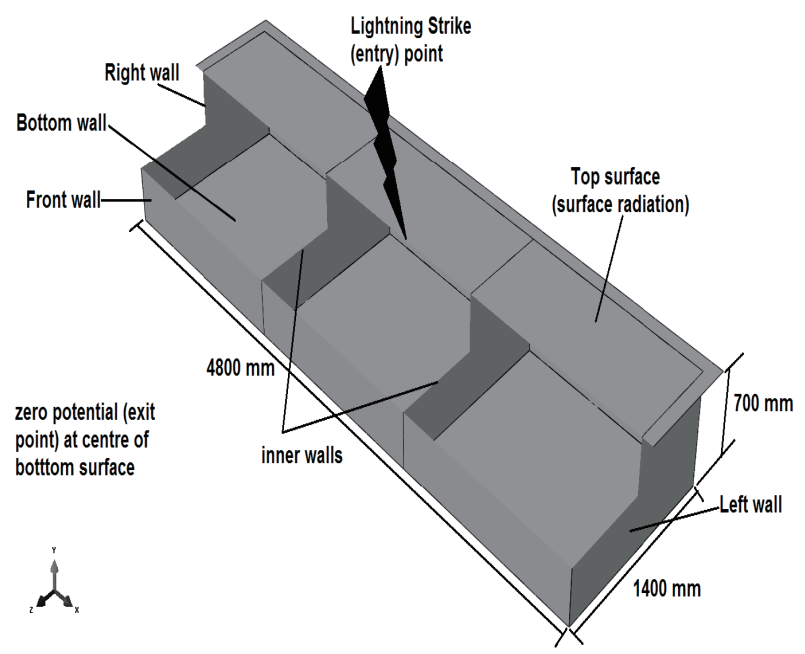

Fig. 3. Fuel tank model with boundary conditions (cut-off view to show inside the fuel tank).

Table 1. Material properties of CFRP and aluminium.

\begin{tabular}{|c|c|c|}
\hline Properties & CFRP & Aluminium \\
\hline \multirow{3}{*}{$\begin{array}{l}\text { Electrical Conductivity } \\
\qquad\left(\Omega^{-1} \mathrm{~mm}^{-1}\right)\end{array}$} & Longitudinal : 29.3 & \multirow{3}{*}{20,000} \\
\hline & Transverse : $7.78 \times 10^{-4}$ & \\
\hline & Through-thickness : $7.94 \times 10^{-7}$ & \\
\hline \multirow{3}{*}{$\begin{array}{l}\text { Thermal Conductivity } \\
\qquad\left(\mathrm{W} \mathrm{mm} \mathrm{mm}^{-1} \mathrm{~K}^{-1}\right)\end{array}$} & Longitudinal : 0.0118 & \multirow{3}{*}{0.138} \\
\hline & Transverse : 0.000609 & \\
\hline & Through-thickness : 0.000609 & \\
\hline Density $\left(\mathrm{kg} \mathrm{mm}^{-3}\right)$ & $1.52 \times 10^{-6}$ & $2.685 \times 10^{-6}$ \\
\hline Joule Heat fraction & 1 & 1 \\
\hline Solidus Temperature (K) & 3,273 & 880 \\
\hline Liquidus Temperature (K) & 3,373 & 922 \\
\hline Specific Heat, $\mathrm{c}_{\mathrm{v}}\left(\mathrm{J} \mathrm{kg}^{-1} \mathrm{~K}^{-1}\right)$ & 1,065 & 880 \\
\hline
\end{tabular}




\subsection{Materials and ply orientations}

The materials used in the tank are 5052-H32 Aluminium and IM600/133 CFRP composites. The material properties of CFRP and aluminium are given in Table $1[14,15]$. The top skin stacking sequences of CFRP I and CFRP II are $\left[45^{\circ} / 0^{\circ} /-\right.$ $\left.45^{\circ} / 90^{\circ}\right] \mathrm{s}$ and $\left[45^{\circ} / 0^{\circ} /-45^{\circ} / 90^{\circ}\right] 2 \mathrm{~s}$, respectively. All the other walls of the tank are assumed to have $0^{\circ}$ ply orientation only. The temperature dependence of the material properties is employed in the analysis. The electrical conductivity of CFRP is assumed to change linearly from $7.94 \times 10^{-7}\left(\Omega^{-1} \mathrm{~mm}^{-1}\right)$ at the decomposition temperature $(873 \mathrm{~K})$ to $0.1\left(\Omega^{-1} \mathrm{~mm}^{-1}\right)$ at the sublimation temperature $(3,273 \mathrm{~K})$ to represent electrical conduction due to other mechanisms [14].

\subsection{Finite element model of the tank}

The finite element model of the fuel tank uses the element type DC3D8E, which is an 8-node linear coupled thermalelectrical brick. The $1 \mathrm{~mm}$ - thick models have 6,812 elements in total and the $2 \mathrm{~mm}$ thick models have 10,700 elements in total. One element per ply in the thickness direction is used up to 4 plies in the CFRP I tank and up to 8 plies in the CFRP II tank. For the remaining region such as side and bottom walls, homogenized orthotropic material properties calculated by the rule of mixture are used.

\section{Results and Discussion}

A computational simulation is carried out for tanks in all the cases for the two lightning strike zones $2 \mathrm{~A}$ and $2 \mathrm{~B}$. The time history of the temperature at the lightning strike (entry) point and the ground (exit) point is studied to identify the maximum temperature attained during the lightning attachment to the fuel tank. For zone 2A analysis, the CFRP fuel tanks reach the maximum temperature of 3,273 K, which is the sublimation temperature of CFRP composites, when the current component $\mathrm{D}$ is used. The following layers do not reach the sublimation temperature but rather the decomposition temperature, $873 \mathrm{~K}$, as shown in Figs. $4 \mathrm{a}$ and 5a. Once the sublimation temperature is reached, holes are created on the CFRP tanks because, above the decomposition temperature, the dielectric breaks down at the interlayer gaps [16] and surface recession occurs [14]. Throughout the analysis, the temperature of CFRP II is slightly less than that of CFRP I.

For zone $2 \mathrm{~B}$ analysis, as shown in Figs. $4 \mathrm{~b}$ and $5 \mathrm{~b}$, the maximum temperature does not reach the sublimation temperature; instead, CFRP I reaches a maximum temperature of 3,129 K whereas CFRP II reaches a maximum temperature of $3,000 \mathrm{~K}$ when the current component $\mathrm{D}$ is used. In this analysis, we find a drop and a rise in the temperature when component $\mathrm{C}$ is used. The component $\mathrm{C}$ in general plays a major role in charge transfer. Here also the temperature of CFRP II is slightly less than that of CFRP I throughout the analysis. The plots show that the time scales of the zone $2 \mathrm{~A}$ and zone $2 \mathrm{~B}$ analyses are different because of the inclusion of current component $\mathrm{C}$ in zone $2 \mathrm{~B}$.

The plot shows that the temperature is higher at the strike point than that at the exit point, but that the temperature at the exit point is considerably higher than at that at any other part of the tank except the strike point. The temperature at the exit point increased because all the currents that enter the fuel tank leave through the exit point. The exit point does

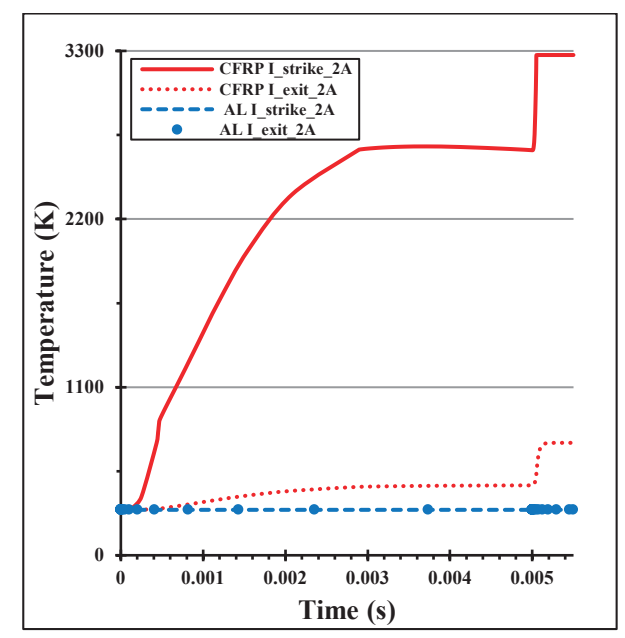

(a) Zone $2 \mathrm{~A}$ analysis

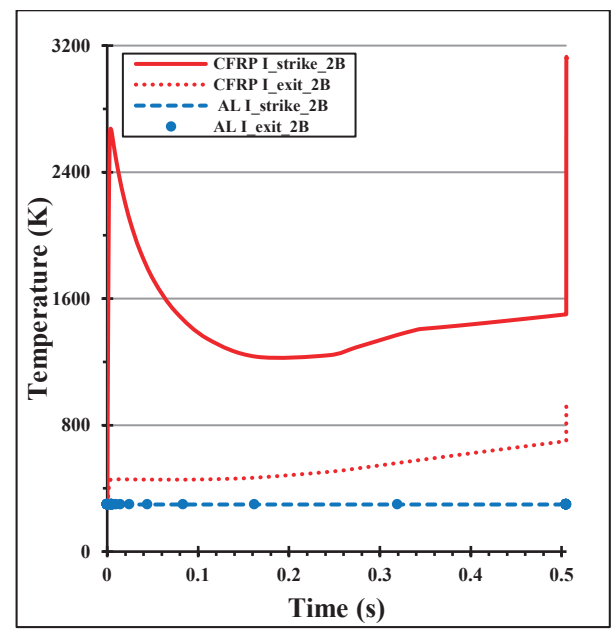

(b) Zone 2B analysis

Fig. 4. Temperature history at the lightning strike and exit points for $1 \mathrm{~mm}$ - thick models. 


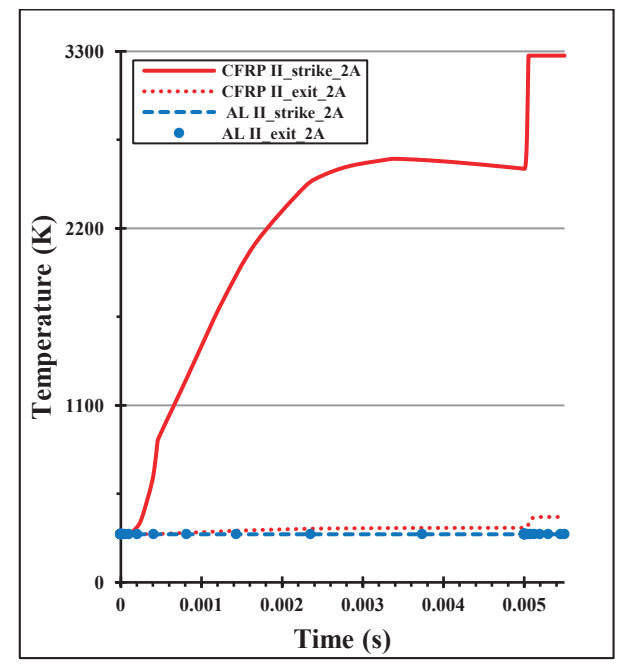

(a) Zone $2 \mathrm{~A}$ analysis

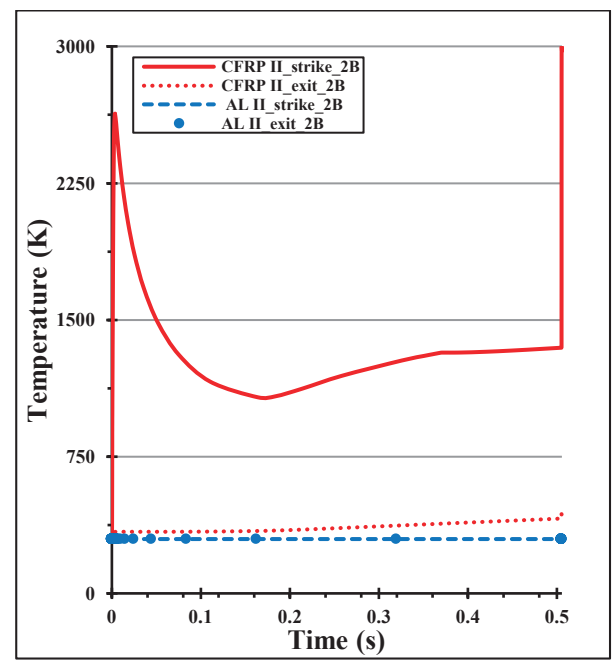

(b) Zone 2B analysis

Fig. 5. Temperature history at the lightning strike and exit points for $2 \mathrm{~mm}$ - thick models.

not need to be at the same point that is considered here and it may be at some other point. Nevertheless, all the results indicate that the temperature will be considerably higher at the exit point. The temperature histories of the aluminium models are also shown for comparison. The aluminium models do not experience any significant temperature rise and remain almost near the ambient temperature.

The temperature distribution on each wall is also studied. The temperature is higher only at the strike point and the exit point, as discussed above. The temperatures at the other areas of the tank do not rise significantly. The auto-ignition temperature for kerosene fuels (Jet A) is considered as 505 $\mathrm{K}\left(450^{\circ} \mathrm{F}\right)$ at static sea level conditions and the maximum allowable surface temperature is $478 \mathrm{~K}\left(400^{\circ} \mathrm{F}\right)$ [6]. Neither the auto-ignition temperature nor the maximum allowable surface temperature is reached anywhere in the regions where the fuel vapour has direct exposure.

The temperature distribution along the depth of the top skin is discussed in detail. In the zone $2 \mathrm{~A}$ analysis, the temperature rise propagates up to a depth of $0.5 \mathrm{~mm}$ for CFRP I and CFRP II. As shown in Fig. 6a, the temperature remains near the ambient temperature below a depth of 0.5 $\mathrm{mm}$, and it is the same as the temperature of the aluminium models. The temperature drop along the depth of the top skin of CFRP I follows the same trend as that of CFRP II.

In the zone $2 \mathrm{~B}$ analysis, the temperature drop trend of

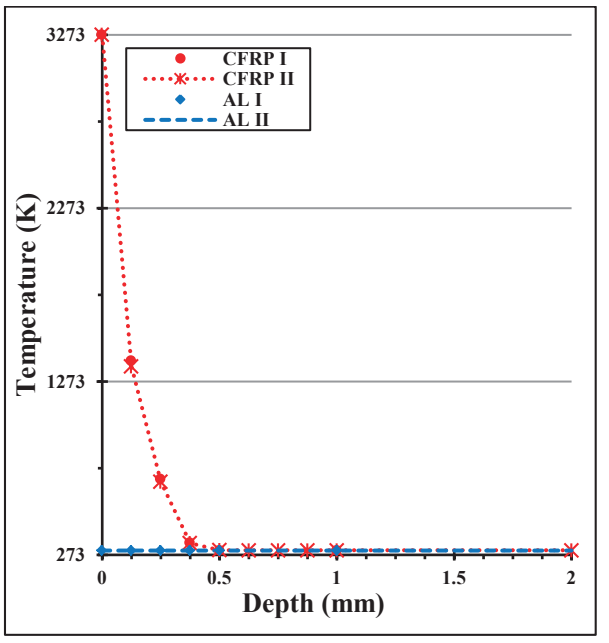

(a) Zone $2 \mathrm{~A}$ analysis

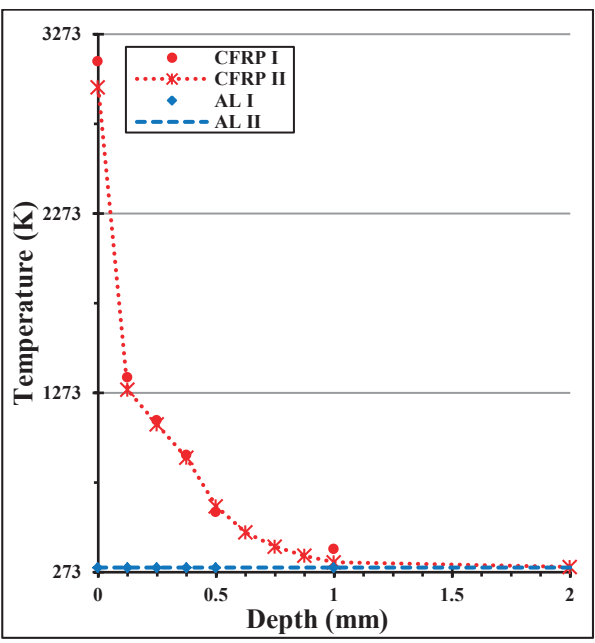

(b) Zone $2 \mathrm{~B}$ analysis

Fig. 6. Temperature along the depth of the top skin (measured from the strike point). 
CFRP I is slightly different from that of CFRP II, as shown in Fig. $6 \mathrm{~b}$. In this case, the temperature rise propagates up to a depth of $1 \mathrm{~mm}$. Beyond $1 \mathrm{~mm}$, the temperature remains near the ambient temperature as in the aluminium models. The temperature contours on the different layers of the top skin in the zone $2 \mathrm{~A}$ analysis are shown in Figs. $7 \mathrm{a}$ and $7 \mathrm{~b}$.

In order to understand clearly the resistive and conductive behaviours of the CFRP composites and aluminium, the electrical energy dissipated in a tank model is studied separately for the CFRP and aluminium tanks. The electrical energy dissipated is given by Joule heat dissipation, which is the heat generated in a material due to the resistance exerted to the current flow in it. The electrical energy dissipation increases the temperature and is proportional to the action integral of the applied current [17].

The electrical energy summed up over an entire model is shown in the plots and the electrical energy is given by the formula

$$
\mathrm{W}=\mathrm{AI} \times \mathrm{R}
$$

where $\mathrm{W}$ is the electrical energy deposited, $\mathrm{R}$ is the resistance (ohms) of the specimen, and $\mathrm{AI}$ is the action integral $\left(\mathrm{A}^{2} \mathrm{~s}\right)$ which is given by the formula

$$
\mathrm{AI}=\int \mathrm{i}^{2} \mathrm{dt}
$$

where $\mathrm{i}$ is the transient lightning current.

The electrical energy dissipated in the aluminium model is significantly lower than that of the CFRP model owing to the good conductivity of aluminium. In both zone $2 \mathrm{~A}$ and zone $2 \mathrm{~B}$ analyses, considering only the CFRP composites, CFRP II shows higher energy dissipation than CFRP I , as shown in Figs. 8a and 9a.

On the other hand, AL II show lower energy dissipation than AL I because of its large volume and very good conductivity, as shown in Figs. $8 \mathrm{~b}$ and $9 \mathrm{~b}$, for both zones. The magnitude of energy dissipated in the zone $2 \mathrm{~B}$ analysis is higher than that in the zone $2 \mathrm{~A}$ analysis. This shows that Joule heating is significant in composites and negligible in metals [18]. Even though the carbon fibres in CFRP composites are good conductors, the polymer matrix, which is an excellent dielectric, reduces the overall conductivity of CFRP composites [19]. The above plots clearly show the very low conductivity of the CFRP composites and explain why the damages incurred by the CFRP skins will be different from those by the aluminium skins. The indirect effects may also be more severe within composites than within
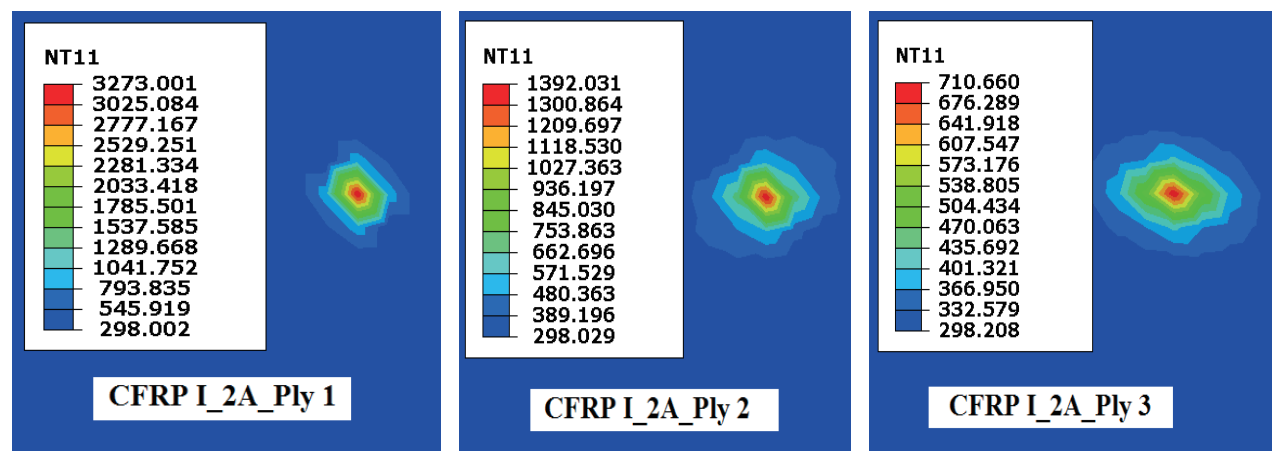

(a) First 3 plies on top skin of CFRP I for zone 2A analysis
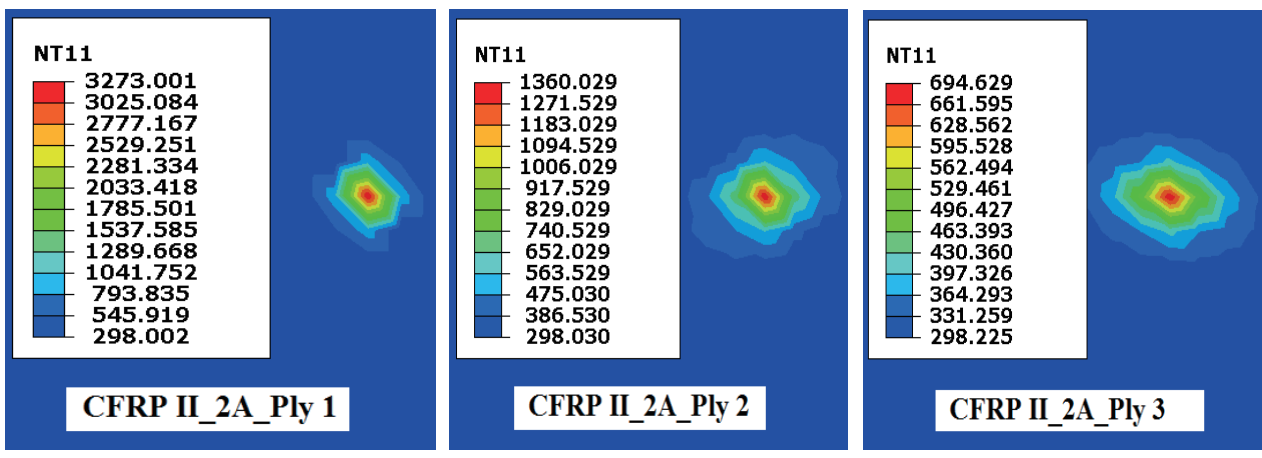

(b) First 3 plies on top skin of CFRP II for zone 2A analysis

Fig. 7. Temperature contours on layers of top skin for zone $2 \mathrm{~A}$ analysis (zoomed-in view). 
aluminium [20].

\section{Concluding Remarks}

We computationally simulated the effects of lightning strikes using a coupled thermal-electrical analysis module and studied the temperature variations in a fuel tank. The temperature plots confirmed that Joule heat generation is significant in composite materials because of their very low conductivity, but negligible in metals due to their high conductivity. A very high temperature rise up to the sublimation temperature $(3,273 \mathrm{~K})$ was observed at the lightning strike point, in the zone $2 \mathrm{~A}$ analyses of both CFRP $\mathrm{I}$ and CFRP II. In the zone $2 \mathrm{~B}$ analyses, the temperature at the strike point reached 3,129 K for CFRP I and 3,000 K for CFRP II. The temperature at the ground point was also significantly higher, indicating that the lightning exit point also experienced a temperature rise.

In addition, the electrical energy dissipation plots clearly explained the nature of conductivity and resistivity in aluminium and CFRP composites. CFRP I was as safe as CFRP II in all aspects and could be chosen as material for fuel tank walls, provided no structural or other constraints exist. The possibility of fuel vapour ignition was very small in all the cases since the auto-ignition temperature of the fuel was not reached anywhere in the areas where fuel vapour had direct exposure. Among the lightning strike zones, zone $2 \mathrm{~B}$ seemed to produce more adverse effects than zone $2 \mathrm{~A}$.

The analysis here was carried out for a simple geometry

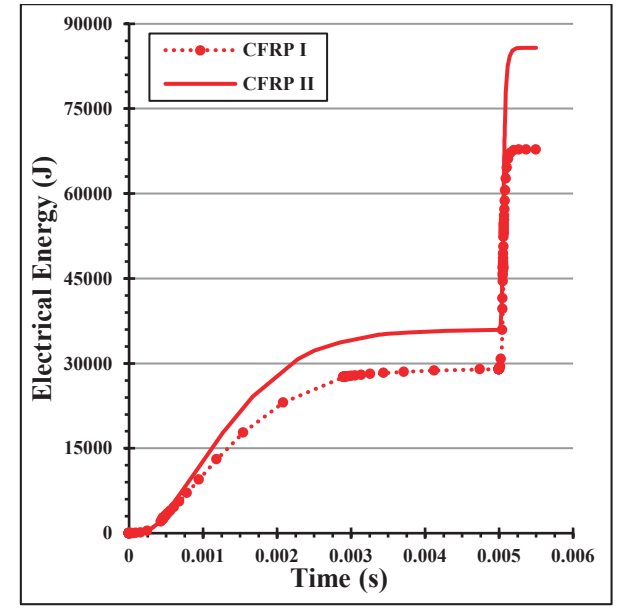

(a) CFRP tank models

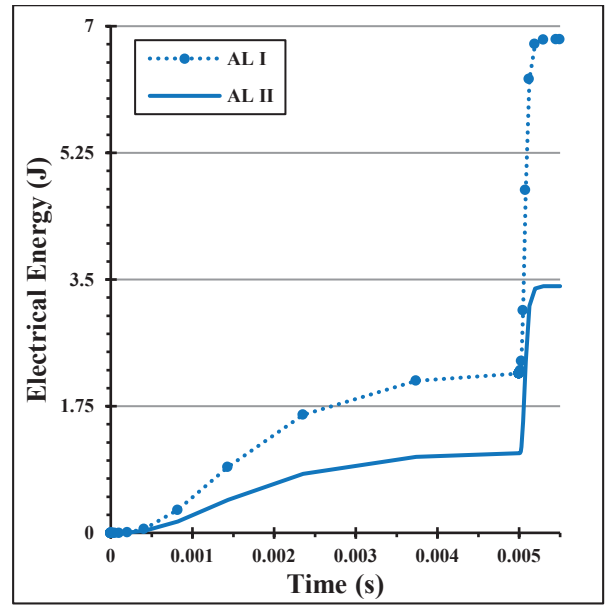

(b) Aluminium tank models

Fig. 8. Electrical energy dissipation plots for zone 2A analysis.

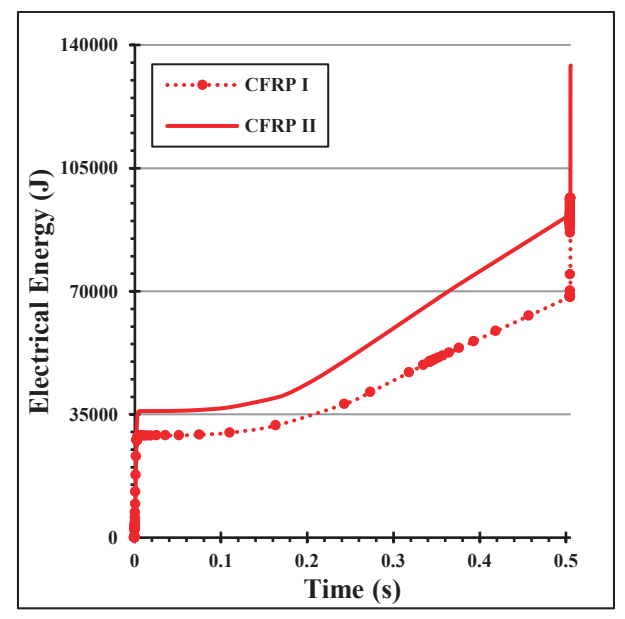

(a) CFRP tank models

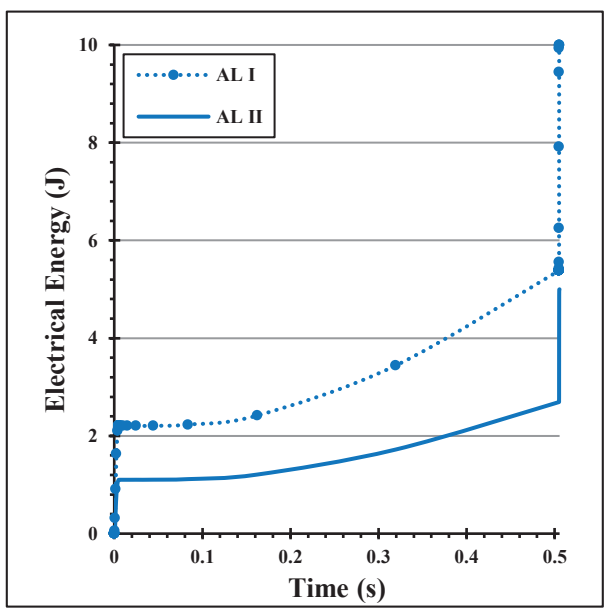

(b) Aluminium tank models

Fig. 9. Electrical energy dissipation plots for zone $2 \mathrm{~B}$ analysis. 
of the fuel tank and for a few selected cases. The coupled thermal-electrical approach can be extended to simulate other geometries with different thickness values and other lightning strike zones as well. This will be the subject of future work.

\section{Acknowledgement}

This work was supported by the KOFST (The Korean Federation of Science and Technology Societies) and partially by the National Research Foundation of Korea (Priority Research Centers Program NRF 2009-009414) funded by the Ministry of Education Science and Technology of South Korea.

\section{References}

[1] Rupke, E., Lightning Direct Effects Handbook, Lightning Technologies Inc., Pittsfield, 2002.

[2] Burrows, B., Haigh, S., Chessum, C., and Dunkley, V., "Lightning Protection Design and Testing of an All Composite Wet Wing for the Egrett," The 1991 International Aerospace and Ground Conference on Lightning and Static Electricity, Vol. 1, 1991.

[3] Kostogorova-Beller, Y., "Physics of Interaction of Lightning Currents with Aluminum Sheets," Journal of Aircraft, Vol. 49, No. 1, 2012, pp. 66-75.

[4] Laroche, P., Blanchet, P., Delannoy, A., and Issac, F., "Experimental Studies of Lightning Strikes to Aircraft," Lightning Hazards to Aircraft and Launchers, Journal Aerospace Lab, AL 05-06, 2012.

[5] Aircraft Lightning Protection Handbook, U. S. Department of Transportation, Federal Aviation Administration, 1989.

[6] Fuel Tank Ignition Source Prevention Guidelines, Advisory Circular, AC No. 25.981-1C, U. S. Department of Transportation, 2008.

[7] Kostogorova-Beller, Y., "Quantification of the Materials's Resistance to Damage by Lightning," Journal of Aircraft, Vol. 50, No. 3, 2013, pp. 827-831.

[8] Condon, E., Aircraft Lightning: Requirements, Component Testing, Aircraft Testing and Certification, The
University of Kansas Continuing Education, Lawrence, 2012.

[9] Plumer, J., "Further Thoughts on Location of Lightning Strike Zones on Aircraft," Lightning Technology, Proceedings of a Technical Symposium at NASA Langley Research Center, Hampton, U.S., 1980, pp. 81-98.

[10] Lalande, P., and Delannoy, A., "Numerical Methods for Zoning Computation," Lightning Hazards to Aircraft and Launchers, Journal Aerospace Lab, AL 05-08, 2012.

[11] Morgan, D., Hardwick, C., Haigh, S., and Meakins, A., "The Interaction of Lightning with Aircraft and the Challenges of Lightning Testing," Lightning Hazards to Aircraft and Launchers, Journal Aerospace Lab, AL 05-11, 2012.

[12] ABAQUS Theory Manual, Coupled Thermal-Electrical Analysis, pp. 2.12.1-1 - 2.12.1-6.

[13] ABAQUS Analysis User's Manual, Coupled ThermalElectrical Analysis, pp. 6.7.3-1 - 6.7.3-11.

[14] Ogasawara, T., Hirano, Y., and Yoshimura, A., "Coupled Thermal-Electrical Analysis for Carbon Fiber/ Epoxy Composites Exposed to Simulated Lightning Current," Composites: Part A, Vol. 41, 2010, pp. 973-981.

[15] ASM Handbook, Vol. 2, Properties and Selection: Nonferrous Alloys and Special-Purpose Materials, pp. 180, 355.

[16] Hirano, Y., Katsumata, S., Iwahori, Y., and Todoroki, A., "Artificial Lightning Testing on Graphite/Epoxy Composite Laminate," Composites: Part A, Vol. 41, 2010, pp. 1461-1470.

[17] Plumer, J., and Robb, J., "The Direct Effects of Lightning on Aircraft," IEEE Transactions on Electromagnetic Compatability, Vol. EMC-24, No. 2, 1982, pp. 158-172.

[18] Chemartin, L., Lalande, P., Peyrou, B., Chazottes, A., Elias, P., Delalondre, C., Cheron, B., and Lago, F., "Direct Effects of Lightning on Aircraft Structure: Analysis of the Thermal, Electrical and Mechanical Constraints," Lightning Hazards to Aircraft and Launchers, Journal Aerospace Lab, AL 05-09, 2012.

[19] Feraboli, P., and Miller, M., "Damage Resistance and Tolerance of Carbon/Epoxy Composite Coupons Subjected to Simulated Lightning Strike," Composites: Part A, Vol. 40, 2009, pp. 954-967.

[20] Rasch, N., User's Manual for AC-20-53A Protection of Airplane Fuel Systems Against Fuel Vapor Ignition Due to Lightning, U. S. Department of Transportation, Federal Aviation Administration, 1984. 